\title{
Retrospective study of intellectual development in children treated for acute lymphoblastic leukaemia
}

\section{CHRISTINE EISER AND RICHARD LANSDOWN}

From the Department of Psychological Medicine, The Hospital for Sick Children, London

SUMMARY Nine younger children (mean age $6 \cdot 3$ years) and 6 older children (mean age $9 \cdot 0$ years), previously treated for acute lymphoblastic leukaemia by cranial irradiation and subsequently by 2 or 3 years of chemotherapy, were assessed in terms of intellectual development in relation to 15 controls, matched individually for age, sex, and social background. All children were functioning within a normal range. The older group of children performed as well as their matched controls in all tasks. However, the younger group tended to perform somewhat below their matched controls, and this applied especially to tasks measuring quantitative, memory, and motor skills, but not to language tasks. It is concluded that there is a continual need to monitor the development of children treated for leukaemia, especially when diagnosed in the 2- to 5-year age range.

The recent advances made in the treatment of acute lymphoblastic leukaemia (ALL) are being increasingly paralleled by a concern for the 'quality of life' of the survivors (Lansky et al., 1975). The present study considers whether the cognitive development of such survivors is at all influenced.

ALL most commonly occurs among young children, with a peak incidence at 4 years (Sutow et al., 1973). Treatment starts with a course of chemotherapy, which achieves a first remission in over $90 \%$ of cases and is now usually followed by a course of CNS irradiation. Chemotherapy is then continued for 2 or 3 years.

Two broad areas which might influence cognitive development can be identified. First, there is a need to assess the impact at an emotional level of the long-term stresses experienced both by the child with a potentially fatal disease, and by his family (Spinetta and Maloney, 1975). Second, little is directly known of any effects on cognitive development of some aspects of the medical treatment. This relates both to the possibility of adverse effects associated with the therapeutic use of CNS irradiation and with long-term administration of antileukaemic drugs.

Although it was earlier believed that certain social experiences of the young child may lead to permanent social or intellectual impairment at a later stage, this view has recently been questioned. Clarke and Clarke (1976) argue that various forms of deprivation in the young are not inevitably associated with

Received 19 November 1976 later impairment. Similarly, Quinton and Rutter (1976) have questioned claims that early hospitalizations are linked with behaviour problems in later childhood.

Other factors lead us to suppose that physical brain damage resulting from the treatment would be negligible. Present knowledge of the rate and course of brain growth, the incidence of recovery from accidental brain injury, and some observations on the effects of irradiation, all suggest that there is little probability of adverse effects on development. Brain growth is greatest before 2 years of age (Davison and Dobbing, 1968), and it is primarily during this period of maximum growth rate that environmental agents are most likely to have damaging effects (Dobbing, 1968). Since all the children in this study were over 2 years when treatment began, we did not expect them to show signs of injury. At the same time it must be noted that even where young children do suffer from some form of brain damage, their recovery is likely to be more complete than that made by an adult suffering a comparable level of injury (Rutter et al., 1970).

As might be expected from the above arguments, children undergoing treatment for leukaemia did not show any deficits in intellectual attainments according to Soni et al. (1975). They report intelligence and achievement test data for two separate groups of children. (1) 14 children treated by CNS irradiation for ALL compared with 19 children with solid tumours treated by irradiation to other sites, and assessed before irradiation and then over an 18-month period. (2) 5 children treated by CNS 
irradiation for ALL compared with 9 children treated for ALL but not by irradiation.

No differences in intelligence levels for either of the above comparisons were found. The length of time for which all children had been treated was, however, short, and no child had actually completed the course of treatment. We feel that the most important question is whether the children who complete this treatment are at all distinguishable from the normal population. We might well expect transient drops in performance, either as a function of the 'sleepy period' following radiotherapy (Freeman et al., 1973), or associated with antileukaemic drugs (Holland et al., 1974). Our concern is not with temporary effects such as these, but with the ultimate level of development achieved by children who have successfully completed the course of treatment.

\section{Patients}

At the time of the study there were 24 children with ALL aged between 5 and 11 years who were attending this hospital and who had discontinued treatment after 2-3 years of chemotherapy. Of these, 6 had been tested within the previous 4 months as part of our pilot work, and were therefore not approached. Another 2 children were excluded because they lived considerable distances from the hospital. For the remainder, all parents were contacted, the purpose of the research explained, and permission asked to assess their child. This was refused in one case. The final sample therefore consisted of 15 children (64\% of those who had completed treatment within this age range).

Testing considerations led us to divide these 15 children into two groups; a younger group of 9 children aged between 5.5 years and 7.6 years (mean $6 \cdot 3$ years), and an older group of 6 children aged between 8.3 and 9.5 years (mean 9.0 years). The younger group were diagnosed when aged 2.6 to 4.5 years (mean 3.10 years) and the older group when aged $5 \cdot 7$ to $6 \cdot 9$ years (mean $6 \cdot 2$ years). Both groups had undergone treatment for similar periods of time; an average of 32 months for the younger group, and of 29 months for the older group. The younger children had been without treatment for slightly longer than the older group (mean 11 months and 6 months, respectively). One child was tested while at the hospital for routine check-ups; the remainder were tested at school. The younger group consisted of 6 girls and 3 boys, and the older group of 3 girls and 3 boys. All children had undergone an initial course of radiotherapy. This involved CNS irradiation in all but 2 (Cases 10, 13, Table 2) who had been treated by craniospinal irradiation.
No child was known to have had meningeal involvement.

In addition, there was a comparison group of healthy children with no history of serious illness. Each child treated for leukaemia was matched individually in terms of age, sex, and social background. For 13 of the 15 children, the comparison child was drawn from the same class at school with as similar a birth date as possible. In 2 cases where this was not possible, the comparison child was taken from a school in a similar social class area, and again chosen on the grounds of being closest in age to the child treated for ALL. There was no difference between the two groups in terms of the number of days of schooling missed in the previous year, which was very low in all cases but one (Case 15).

\section{Methods}

All children were first assessed using a standardized intelligence test; in the case of the older group this was the Wechsler Intelligence Scale for Children (WISC), and for the younger group we used the McCarthy (1970) scale. This is designed to measure the child's ability in five areas, and includes subscales to assess verbal, performance, quantitative, memory, and motor skills. The sum of the first three scales is taken as a General Cognitive Index (GCI). (For the age range 6.0 to 6.6 years, the correlation between this and an IQ score derived from the Wechsler Preschool and Primary Scale of Intelligence is $0 \cdot 71$.)

Reading was assessed using the Burt scale. In addition, the older children attempted a short paired-associate learning task. This consisted of a list of 7 pairs of words, read slowly to the child for a maximum of four trials. The number of pairs correctly recalled after four trials was recorded or, where appropriate, the number of trials required before all pairs were correctly recalled. Teachers of the 13 children who had been treated for leukaemia and tested in school were then interviewed briefly to try to identify any behavioural or social problems.

\section{Results}

Standardized scores obtained on the WISC and McCarthy scales for the older and younger children are shown in Tables 1 and 2 respectively. Among the older children treated for leukaemia, only 1 was below average for his age, and 4 obtained full scale scores $1 \mathrm{SD}$ above the mean. There were no significant differences between the two older groups of children on any of the subtests of the WISC scale, nor in terms of the number of words correctly read 
Table 1 Summary table for older children treated for leukaemia $(L)$ and their controls $(C)$

\begin{tabular}{|c|c|c|c|c|c|c|c|c|c|c|c|c|}
\hline \multirow{3}{*}{ Case no. } & \multicolumn{2}{|c|}{ Verbal } & \multicolumn{2}{|c|}{ Performance } & \multicolumn{2}{|c|}{ Full scale } & \multicolumn{2}{|c|}{ Reading } & \multicolumn{4}{|c|}{ Learning } \\
\hline & \multirow[t]{2}{*}{$\boldsymbol{L}$} & \multirow[t]{2}{*}{$C$} & \multirow[t]{2}{*}{$\boldsymbol{L}$} & \multirow[t]{2}{*}{$C$} & \multirow[t]{2}{*}{$L$} & \multirow[t]{2}{*}{$C$} & \multirow[t]{2}{*}{$L$} & \multirow[t]{2}{*}{$C$} & \multicolumn{2}{|c|}{$\begin{array}{l}\text { Trials to } \\
\text { criterion }\end{array}$} & \multicolumn{2}{|c|}{$\begin{array}{l}\text { No. correct after } \\
\text { 4. trials }\end{array}$} \\
\hline & & & & & & & & & $\boldsymbol{L}$ & $C$ & $L$ & $C$ \\
\hline $\begin{array}{l}1 \\
2 \\
3 \\
4 \\
5 \\
6 \\
\text { Mean }\end{array}$ & $\begin{array}{r}97 \\
109 \\
110 \\
124 \\
129 \\
92 \\
110\end{array}$ & $\begin{array}{r}97 \\
103 \\
124 \\
124 \\
133 \\
105 \\
114\end{array}$ & $\begin{array}{r}97 \\
122 \\
132 \\
120 \\
125 \\
86 \\
113\end{array}$ & $\begin{array}{l}101 \\
110 \\
128 \\
111 \\
142 \\
124 \\
119\end{array}$ & \begin{tabular}{r|}
97 \\
117 \\
123 \\
124 \\
133 \\
88 \\
113
\end{tabular} & $\begin{array}{r}99 \\
107 \\
139 \\
120 \\
141 \\
115 \\
119\end{array}$ & $\begin{array}{l}42 \\
65 \\
54 \\
70 \\
92 \\
19\end{array}$ & $\begin{array}{l}44 \\
32 \\
52 \\
77 \\
73 \\
45\end{array}$ & $\begin{array}{l}\mathbf{3} \\
\mathbf{3} \\
\mathbf{3} \\
\mathbf{1}\end{array}$ & $\begin{array}{l}3 \\
2 \\
1 \\
3\end{array}$ & 5 & $\begin{array}{l}3 \\
5\end{array}$ \\
\hline
\end{tabular}

Table 2 Summary table of standardized scores for younger children treated for leukaemia $(L)$ and their controls $(C)$

\begin{tabular}{|c|c|c|c|c|c|c|c|c|c|c|c|c|c|c|}
\hline \multirow[t]{2}{*}{ Case no. } & \multicolumn{2}{|c|}{ Verbal } & \multicolumn{2}{|c|}{ Performance } & \multicolumn{2}{|c|}{ Quantitative } & \multicolumn{2}{|l|}{$G C I$} & \multicolumn{2}{|c|}{ Memory } & \multicolumn{2}{|c|}{ Motor } & \multicolumn{2}{|c|}{$\begin{array}{l}\text { Reading } \\
\text { (no. of words) }\end{array}$} \\
\hline & $L$ & $C$ & $L$ & $\dot{C}$ & $\boldsymbol{L}$ & $C$ & $L$ & $C$ & $\boldsymbol{L}$ & $C$ & $L$ & $C$ & $L$ & $C$ \\
\hline $\begin{array}{l}7 \\
8 \\
9 \\
10 \\
11 \\
12 \\
13 \\
14 \\
15 \\
\text { Mean }\end{array}$ & $\begin{array}{l}52 \\
49 \\
39 \\
69 \\
69 \\
49 \\
43 \\
38 \\
41 \\
49 \cdot 8\end{array}$ & $\begin{array}{l}57 \\
58 \\
56 \\
57 \\
59 \\
54 \\
60 \\
61 \\
40 \\
55 \cdot 8\end{array}$ & $\begin{array}{l}40 \\
54 \\
38 \\
60 \\
61 \\
40 \\
56 \\
62 \\
33 \\
49 \cdot 3\end{array}$ & $\begin{array}{l}55 \\
47 \\
77 \\
69 \\
62 \\
76 \\
78 \\
51 \\
43 \\
62 \cdot 0\end{array}$ & $\begin{array}{l}50 \\
43 \\
39 \\
52 \\
54 \\
38 \\
46 \\
30 \\
37 \\
41 \cdot 1\end{array}$ & $\begin{array}{l}57 \\
58 \\
60 \\
63 \\
51 \\
52 \\
54 \\
54 \\
40 \\
54 \cdot 3^{*}\end{array}$ & $\begin{array}{c}96 \\
98 \\
81 \\
108 \\
127 \\
86 \\
96 \\
89 \\
74 \\
95 \cdot 0\end{array}$ & $\begin{array}{l}114 \\
109 \\
124 \\
124 \\
116 \\
120 \\
130 \\
112 \\
83 \\
114 \cdot 6 *\end{array}$ & $\begin{array}{l}56 \\
42 \\
50 \\
58 \\
59 \\
39 \\
41 \\
42 \\
38 \\
47 \cdot 2\end{array}$ & $\begin{array}{l}63 \\
53 \\
56 \\
62 \\
59 \\
64 \\
53 \\
58 \\
43 \\
56 \cdot 8 \dagger\end{array}$ & $\begin{array}{l}50 \\
56 \\
31 \\
60 \\
46 \\
52 \\
43 \\
53 \\
47 \\
48 \cdot 7\end{array}$ & $\begin{array}{l}59 \\
69 \\
65 \\
73 \\
71 \\
67 \\
76 \\
62 \\
58 \\
66 \cdot 7 \dagger\end{array}$ & $\begin{array}{r}3 \\
24 \\
32 \\
35 \\
51 \\
8 \\
30 \\
4 \\
12\end{array}$ & $\begin{array}{r}3 \\
29 \\
60 \\
57 \\
21 \\
34 \\
52 \\
11 \\
5\end{array}$ \\
\hline
\end{tabular}

The GCI (General Cognitive Index) is based on a mean score of 100 .

Verbal, performance, quantitative, memory, and motor scales are based on a mean score of 50 .

$* \mathbf{P}<0.02 ;+\mathbf{P}<0.01$.

in the Burt scale. There was no difference, either, in the number of pairs of words correctly recalled in the learning task. As measured by these tests, therefore, there are no apparent signs of intellectual impairment among our group of older children.

Table 2 gives the results for the younger group. The mean GCI score for the group treated for leukaemia was $95 \cdot 0$. This is a little lower than expected for a normal population (mean 100), but not so low that we need assume that the children treated for leukaemia derive from a population whose mean is lower (a mean score of $<92 \cdot 2$ would be expected in this case). Only 1 child scored significantly above the mean, 5 at an average level, and 3 scored at least 1 SD below the mean. As a whole the group do not differ significantly from a normal population, though their scores do tend to be at a level below average. It must also be noted that the standardized norms for the McCarthy scale are based on a population of American children, and also take no account of differences in individual scores which might arise from higher social class, for example. To take account of such differences, we subsequently compared the performance of each child treated for leukaemia with another child matched in age, sex, and social background. The score for each treated child was subtracted from the nontreated, matched, control child for the GCI and each of the subtests of the McCarthy scale. A positive difference score implied that the healthy child scored higher than the treated child, and vice versa. A series of Wilcoxon tests (Ferguson, 1966) was then conducted on these difference scores.

The GCI was higher for the healthy children $(t=2.5, P<0.02)$. This difference was also reflected on the component subscales; the healthy children scored higher on the quantitative $(t=1 \cdot 5$, $P<0.02)$, memory $(t=0, P<0.01)$, and motor scales $(t=0, P<0.01)$. Only on the verbal scales $(t=12, N S)$, performance $(t=7, P<0.06)$, and Burt Reading Test $(t)=10, N S)$ were there no significant differences between the groups. (It should be noted, however, that these results largely reflect the very superior verbal skills of one of the treated children, Case 12.) On all scales the treated children scored lower, on average, than the controls.

As each of the memory and motor scales described above are composed of six different items, we conducted further analyses to see which contributed most to these results. For the memory scale, the task 
most clearly distinguishing the two groups was the ability to recall digits read backwards $(t=3 \cdot 0$, $P<0.02)$. For the motor scale, children treated for leukaemia tended to do badly on tasks both of gross and fine motor skills. They scored significantly worse than the controls on tasks of leg co-ordination $(\mathrm{t}=0, \mathrm{P}<0.01)$, arm co-ordination $(\mathrm{t}=0$, $P<0.01$ ), and on fine skills measured by a shapes copying task $(t=1 \cdot 0, P<0 \cdot 01)$.

Although all the control children showed clear evidence of established hand dominance, 2 of the treated children were of mixed dominance. Scores in the learning task were only obtained for 8 out of the 10 possible pairs of children. There was no overall difference between the groups in terms of the numbers of words correctly recalled after four trials.

We then conducted a series of correlations, separately for the two age groups, between the treated children's scores on all tests and (1) the age of diagnosis, (2) months undergoing treatment, and (3) months since treatment was completed. None was significant.

Teachers' reports which were available for 13 out of the 15 children treated for leukaemia suggest that none was seen as a behaviour problem in school. 2 did not generally participate in any sport or games lessons; the remainder were said to be included in all school activities. One child went to a remedial teacher twice a week, and one had been kept in a younger class for a second year. Most commonly, the children were described as 'shy, quiet, and withdrawn' $(71 \%)$; they tended not to mix well and to have few friends $(71 \%)$, though in one case this was attributed to the parents' overprotectiveness. They tended to be popular with teachers, however. Most children were described as pleasant and polite $(86 \%)$.

\section{Discussion}

Our data extend the findings of Soni et al. (1975) that there are no gross signs of intellectual impairment in children treated for ALL. While Soni et al. were concerned only with children undergoing treatment, our own data relate to children who had completed the whole course of treatment. In this study children who were diagnosed after the age of 5 years tended to perform above the average for their age and as well as their matched controls. As far as we can tell from these data it seems that the intellectual abilities of these children have not been impaired either by emotional disturbances associated with the disease, or by the treatment itself.

We do, however, have some reservations about the younger group of children. They tended to function somewhat below average for their age, and consistently below the performances of their matched controls. For Case 14 this may be accounted for by recent extended absences from school. For the remaining children, however, the possibility of very slight generalized impairment cannot be completely rejected. We feel that close monitoring of the development of children treated for ALL, especially if diagnosed between 2 and 5 years, is called for.

Whether the cause of this can be attributed directly to radiotherapy rather than chemotherapy, the course of the disease itself, or indirectly to emotional factors cannot be answered by these data. One variable that can be excluded as a general factor, however, is amount of schooling. During the past year the children with ALL had no more time away from school than the control children. In fact, the younger group had missed very little school, many of them having completed treatment while still in infant schools. While the younger group did worse on average than their controls, it is the older group who would have tended to miss longer periods at school, and this group compared very favourably with their controls.

It might be argued that we are not dealing with a problem specific to children treated for leukaemia, but rather that any group of children suffering from a disease early in life is more likely to show impairment than children suffering the same disease at a later age. Research on this question is somewhat restricted for our purposes, as it has tended to be dominated by the assumption that impairment from outside agents is most likely to occur for children under 2 years. Even so, Wilner et al. (1969), for example, found no relation between the incidence of minor neurological signs and the occurrence of measles before or after 2 years of age. Research, such as this, does not tend to support the hypothesis that the occurrence of a disease in younger children is necessarily more harmful than its occurrence among older groups.

On the whole the children in this study appear to have survived leukaemia and its treatment far better than the group of long-term survivors investigated by Meadows and Evans (1976). They report that only 9 out of 23 patients surviving 5 years beyond diagnosis had no psychiatric or psychological signs of abnormality, and none of these 9 had been treated by CNS irradiation. For children who had been treated by radiotherapy there was a higher incidence of mild and more severe clinical pathology, and only one of 5 children assessed psychologically was reported to be 'normal'. Our own work suggests that children treated for ALL can recover with fewer adverse effects than implied by Meadows and Evans. The critical distinction between the two studies is presumably that between patients still 
undergoing treatment after 5 years and those who completed treatment within that time. Even so, our results do imply that there are at least some children who can be expected to survive over the relatively long-term (i.e. 4-5 years) without gross psychological ill effects.

It would be premature to consider whether our results can be generalized for all children treated for ALL. It is clear, however, that we can expect differential effects of CNS irradiation depending on the maturational level of the child (Hicks and D'Amato, 1966). In the absence of fuller information regarding the nature of the relation between brain structure and function, more systematic monitoring of the development of these children is called for. We do not mean to suggest that there are gross levels of impairment among all children treated for leukaemia by CNS irradiation and chemotherapy, but rather that within the group as a whole some children are more 'at risk' than others. Research should be directed towards isolating the factors common to this 'at risk' group.

We thank Professor P. Graham, Professor R. M. Hardisty, Dr. J. M. Chessells, and Mrs. M. Lobascher for advice, and Miss P. Sorene, secretary. This work was financed by a grant from the Medical Research Council.

\section{References}

Clarke, A. M., and Clarke, A. D. B. (1976). Early Experience. Open Books, London.

Davison, A. N., and Dobbing, J. (1968). The developing brain. Applied Neurochemistry, p. 253. Ed. by A. N. Davison and J. Dobbing. Blackwell, Oxford.

Dobbing, J. (1968). Vulnerable periods in the developing brain. Applied Neurochemistry, p. 287. Ed. by A. N. Davison and J. Dobbing. Blackwell, Oxford.
Ferguson, G. A. (1966). Statistical Analysis in Psychology and Education, pp. 360-361. McGraw Hill, New York.

Freeman, J. E., Johnston, P. G. B., and Voke, J. M. (1973). Somnolence after prophylactic cranial irradiation in children with acute lymphoblastic leukaemia. British Medical Journal, 4, 523-525.

Hicks, S. P., and D'Amato, C. J. (1966). Effects of ionizing radiations on mammalian development. Advances in Teratology, 1, 195-250.

Holland, J., Fasanello, S., and Ohnuma, T. (1974). Psychiatric symptoms associated with $\mathrm{L}$-asparaginase administration. Journal of Psychiatric Research, 10, 105-113.

Lansky, S. B., Lowman, J. T., Vats, T., and Gyulay, J. E. (1975). School phobia in children with malignant neoplasms. American Journal of Diseases of Children, 129, 42-46.

McCarthy, D. (1970). McCarthy Scales of Children's Abilities. Psychological Corp., New York.

Meadows, P. T., and Evans, A. E. (1976). Effects of chemotherapy on the central nervous system. A study of parenteral methotrexate in long-term survivors of leukemia and lymphoma in childhood. Cancer, 37, 1079-1085.

Quinton, D., and Rutter, M. (1976). Early hospital admissions and later disturbances of behaviour: an attempted replication of Douglas' findings. Developmental Medicine and Child Neurology, 18, 447-459.

Rutter, M., Graham, P., and Yule, W. A. (1970) Neuropsychiatric Study in Childhood. Clinics in Developmental Medicine, No. 35-36. Heinemann, London.

Soni, S. S., Marten, G. W., Pitner, S. E., Duenas, D. A., and Powazek, M. (1975). Effects of central-nervous-system irradiation on neuropsychologic functioning of children with acute lymphocytic leukemia. New England Journal of Medicine, 293, 113-118.

Spinetta, J. J., and Maloney, L. J. (1975). Death anxiety in the out-patient leukemic child. Pediatrics, 56, 1034-1037.

Sutow, W. W., Vietti, T. J., and Fernbach, D. J. (1973). (Editors.) Clinical Pediatric Oncology. Mosby, St. Louis.

Wilner, E., Cannon, J., and Brody, J. A. (1969). Measles, minor neurological signs and intelligence. Developmental Medicine and Child Neurology, 11, 449-454.

Correspondence to Dr. C. Eiser, Department of Psychological Medicine, The Hospital for Sick Children, Great Ormond Street, London WC1N 3JH. 